\title{
Survey on the Quality of the Top-Selling European and American Botanical Dietary Supplements Containing Boswellic Acids
}

\author{
Authors \\ Jürgen Meins ${ }^{1}$, Christian Artaria ${ }^{2}$, Antonella Riva ${ }^{2}$, Paolo Morazzoni ${ }^{2}$, Manfred Schubert-Zsilavecz ${ }^{3}$, \\ Mona Abdel-Tawab \\ Affiliations \\ ${ }^{1}$ Central Laboratory of German Pharmacists, Eschborn, Germany \\ ${ }^{2}$ Indena S. p. A., Milano, Italy \\ ${ }^{3}$ Department of Pharmaceutical Chemistry, Goethe-University Frankfurt, Frankfurt am Main, Germany
}

\author{
Key words \\ - Boswellia \\ - Burseraceae \\ - boswellic acids \\ - frankincense \\ - botanical dietary supple- \\ ments \\ - herbal supplements
}

received October 13, 2015

revised February 9, 2016

accepted February 10, 2016

\section{Bibliography}

DOI http://dx.doi.org/

10.1055/s-0042-103497

Published online April 7, 2016

Planta Med 2016; 82: 573-579

(C) Georg Thieme Verlag KG

Stuttgart · New York .

ISSN 0032-0943

\section{Correspondence}

Assoc. Prof. Dr. Mona

Abdel-Tawab

Central Laboratory of German

Pharmacists

Carl-Mannich-Str. 20

65760 Eschborn

Germany

Phone: + 496196937955

Fax: + 496196937810

m.tawab@zentrallabor.com

\section{Abstract}

$\nabla$

In consideration of the increasing popularity of frankincense and the widely published quality problems associated with botanical dietary supplements, a survey was conducted for the first time on the quality of frankincense containing botanical dietary supplements. Six US products representing $78 \%$ of the units sold and $70 \%$ of the market value, and 11 European products representing $30 \%$ of the units sold and $40 \%$ of the market value were tested for their boswellic acid composition profile, label compliance, and claimed health benefits. Special focus was also set on the statements made with regard to the frankincense applied.

Only five products out of seventeen disclosed all relevant information for the Boswellia extract, mentioning the species, the part of plant used, and the boswellic acid content. Whereas all products but one claimed to use Boswellia serrata, three products did not mention the resin as the part applied and 10 products did not declare the boswellic acid content. Apart from the different boswellic acid composition determined with a sensitive LC/MS method, $41 \%$ of the products did not comply with the label declaration. Hence, one product from Italy did not contain any of the six characteristic boswellic acids (KBA, AKBA, $\alpha \mathrm{BA}$, $\beta B A, A \alpha B A, A \beta B A$ ) at all and another US product contained only traces, suggesting the absence of frankincense or the use of Boswellia frereana instead of B. serrata. In another product, the ratios of the individual boswellic acids were different from $B$. serrata gum resin, indicating the use of

\section{Introduction}

$\nabla$

With millions of people using medicinal plants worldwide, the market of herbal supplements is witnessing a steady growth. Recent data indicate another species such as Boswellia sacra or Boswellia carterii. Furthermore, two products revealed different boswellic acid contents from those declared on the label. Further, two products did not declare the use of manipulated Boswellia gum resin extract being enriched in acetyl-11-keto-boswellic acid content reaching up to $66 \%$. In addition, consumers could be misled by outdated literature or references to in vitro studies performed at dosages that can never be achieved in humans following oral administration.

In summary, this survey reveals that in spite of increased regulations on botanical dietary supplements, the problem of mislabeling still exists and needs to be addressed by the manufacturers, so that consumers get greater confidence in the botanical dietary supplements they use.

\section{Abbreviations \\ $\nabla$ \\ $\alpha$-BA: $\quad$ alpha-boswellic acid \\ A $\alpha$ BA: acetyl- alpha-boswellic acid \\ ABBA: acetyl- beta-boswellic acid \\ AKBA: acetyl-11-keto-boswellic acid \\ B-BA: beta-boswellic acid \\ BAs: boswellic acids \\ catG: cathepsin $\mathrm{G}$ \\ IL: interleukin \\ KBA: 11-keto-boswellic acid \\ 5-LO: 5-lipoxygenase}

mPGES-1: microsomal prostaglandin E synthase-1

SIM: $\quad$ single ion mode

that in $2012,17.9 \%$ of all US adults used botanical supplements [1]. In Germany, $90 \%$ of the people use natural medicines at some time during their life and over $50 \%$ of the population has done so in other European countries [2,3]. Thus, the glob- 
al market for herbal dietary supplements or phytomedicines, estimated at approximately US\$ 60 billion in 2000, is expected to increase dramatically, reaching US $\$ 107$ billion by the year 2017 [4].

At the same time, episodes of contamination (with insecticides, pesticides, synthetic drugs, heavy metals) or adulteration (substituting one plant for another either purposefully or through misidentification) have been frequently reported, resulting in increased concerns about the safety, effectiveness, and quality of herbal products [5]. A study on selected commercial ginseng products marketed as botanical supplement in North America showed that the ginsenoside contents of 232 Panax ginseng C.A. Mey. (Araliaceae) and 81 Panax quinquefolius L. supplements ranged from $0.00 \%$ to $13.54 \%$ and from $0.009 \%$ to $8.00 \%$, respectively, and that $26 \%$ of these products did not meet label claims [6]. Studies on the quality of St. John's wort (Hypericum perforatum L., Hyperiaceae) products showed hypericin content ranging from $22 \%$ to $140 \%$ of the label claim [7]. Similarly, silymarin, an extract from the seeds of milk thistle [Silybum marianum (L.) Gaertn., Asteraceae], was detected at $58-116 \%$ of the labeled claim [8].

Aside from ginseng, St. John's wort, and milk thistle, frankincense is counted among the well-established botanical dietary supplements. This is mainly attributed to the anti-inflammatory properties of frankincense [9] and the growing prevalence of symptoms like joint pain and stiffness in a progressively ageing Western population [10]. Hence, it was shown that a number of pivotal enzymes in inflammation like 5-LO, catG, and mPGES-1 as well as NF- $\kappa$ B and several cytokines like TNF $\alpha$, IL- $1 \beta$, and IL- 6 are inhibited by BAs, the main active ingredients of frankincense ( $\bullet$ Fig. 1). Whereas in the past the anti-inflammatory effects were mainly attributed to the inhibition of 5-LO by AKBA [11], recent research revealed the relevance of the whole fraction of triterpenoid acids and the involvement of much more molecular targets than only 5-LO, especially catG and mPGES-1 $[9,12-15]$. Commercially available frankincense consists of the oleo gum resin obtained from trees of Boswellia serrata Roxb. ex Colebr. (native to India), Boswellia carterii Birdw., and Boswellia frereana Birdw. (native to Africa) as well as Boswellia sacra Flueck (native to Southern Arabia) from the family Burseraceae. The complete spectrum of the characteristic BAs may be found in frankincense obtained from $B$. serrata, B. carterii, and B. sacra, however, the BA composition profiles differ according to the source of the gum resin. On the other hand, frankincense obtained from $B$. frereana does not contain appreciable amounts of the characteristic BAs [16]. Of the gum resins mentioned above, especially the gum resin of $B$. serrata has been traditionally used in Ayurvedic medicine and was thus most extensively investigated in animal as well as in clinical studies.

Against the background of the increasing popularity of frankincense and the widely published quality problems associated with botanical dietary supplements, a survey was conducted for the first time on the quality of the top-selling botanical dietary supplements containing frankincense in the USA and in Europe. In order to identify the botanical dietary supplements sold most in the USA, the 52-week sales ending 28 December 2014 provided by the market research company SPINS for all products containing Boswellia were purchased. Based on these data, six of the most sold US products in natural product supermarkets representing $78 \%$ of the units sold and $70 \%$ of the market value as reported by SPINS were selected. Similarly, to select the most relevant botanical dietary supplements in Europe, the market data

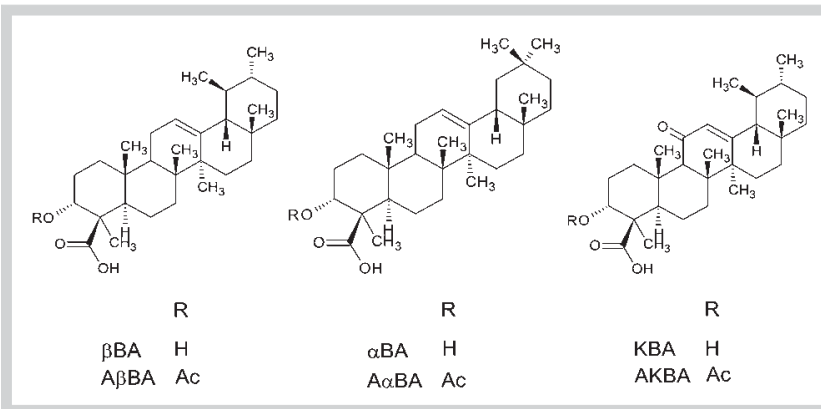

Fig. 1 Chemical structures of the six characteristic BAs.

for 2014 were purchased from the market research company IMS OTC and 11 European products representing $30 \%$ of the units sold and $40 \%$ of the market value as reported by IMS OTC were tested for their BAs composition profile, label compliance, and propagated health claims.

\section{Results and Discussion \\ $\nabla$}

As BAs represent the major pharmacologically active ingredients of frankincense, 17 of the most popular botanical dietary supplements in the American and European supermarkets/outlets claiming to contain frankincense have been analyzed for their BA composition profile using a sensitive LC/MS method. Special focus was also set on the statements made on the label or on the leaflet with regard to the frankincense applied. Fourteen products contained a mixture of Boswellia extract with up to 10 other ingredients comprising vitamins, minerals, glucosamine, methylsulfonylmethane (MSM), collagen, condroitin sulphate, or other plant extracts. Only three products were solely composed of Boswellia extract.

An overview on the products included in this survey is given in - Table 1 and the BAs composition profile of the individual products is presented in $\odot$ Fig. 2. Given that for the production of an extract several Boswellia species may be used, the Boswellia species and the part of the plant applied as well as the content of BAs is of upmost importance. In fact, five products out of seventeen $(3,5,10,12,16)$ disclosed all this information. Whereas all products but one (7) claimed to use $B$. serrata, two products $(6,8)$ did not declare the part of the plant applied nor the BAs content, eight products $(\mathbf{1}, \mathbf{2}, \mathbf{4}, \mathbf{9}, \mathbf{1 1}, \mathbf{1 3}, \mathbf{1 4}, \mathbf{1 5})$ did not make declarations on the BAs content, but on the part used, and one product (17) did not declare the part of the plant applied, but the BAs content. Moreover, the composition profile revealed that the BAs differed greatly, suggesting the use of other Boswellia sources than that declared on the package in the case of seven products. According to a previously carried out analysis of different authenticated gum resins of Boswellia species by Frank and Unger, B. serrata contains the complete spectrum of the characteristic six BAs, whereas $B$. frereana does not contain appreciable amounts of the six BAs at all. On the other hand, the ratio of the signal intensities of the non-acetylated ( $\alpha$-BA, $\beta$-BA) to the acetylated BAs (A $\alpha \mathrm{BA}$ and $A \beta B A$ ) is $<1$ in the case of frankincense extracts from $B$. carterii and $B$. sacra, but is $>1$ in the case of frankincense extracts from $B$. serrata [16]. Based on that background, one product from Italy (11) not containing any of the six BAs (KBA, AKBA, $\alpha$-BA, $\beta$-BA, $\mathrm{A} \alpha \mathrm{BA}$, and $\mathrm{A} \beta \mathrm{BA}$ ) at all and another product from USA (2) 

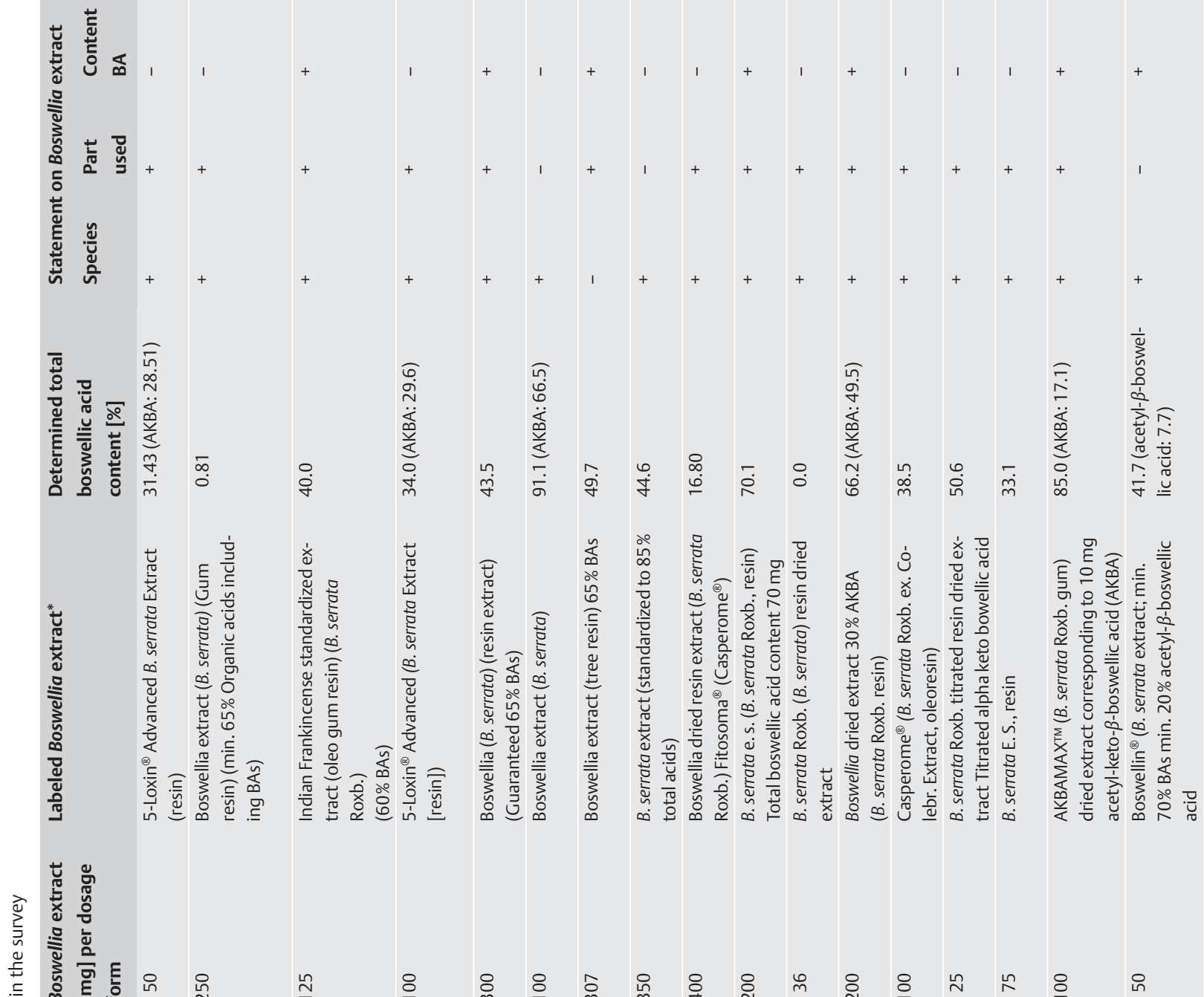

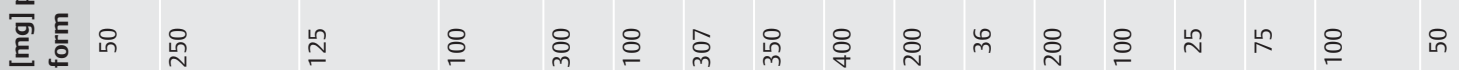

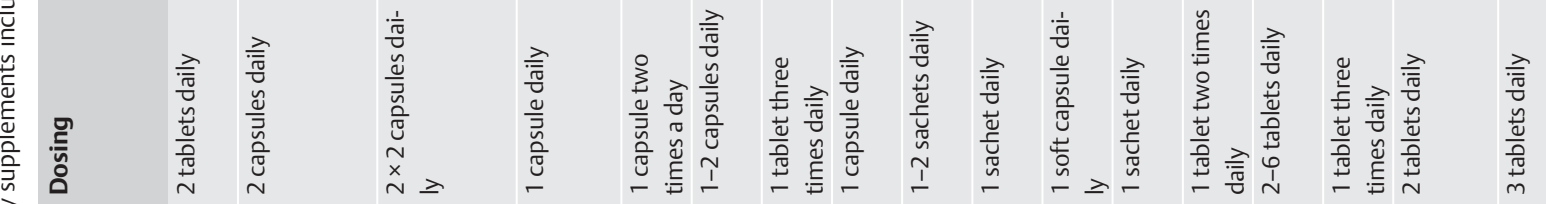
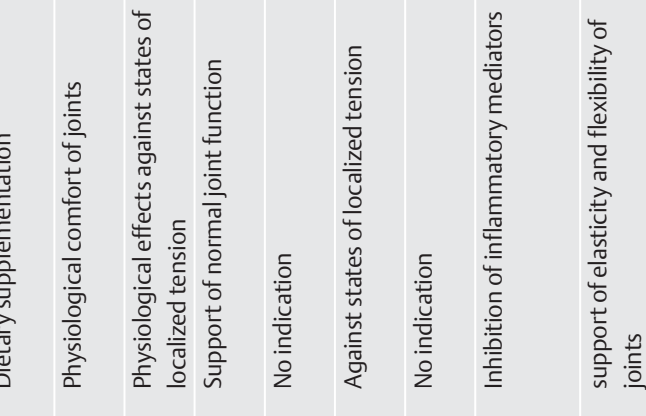


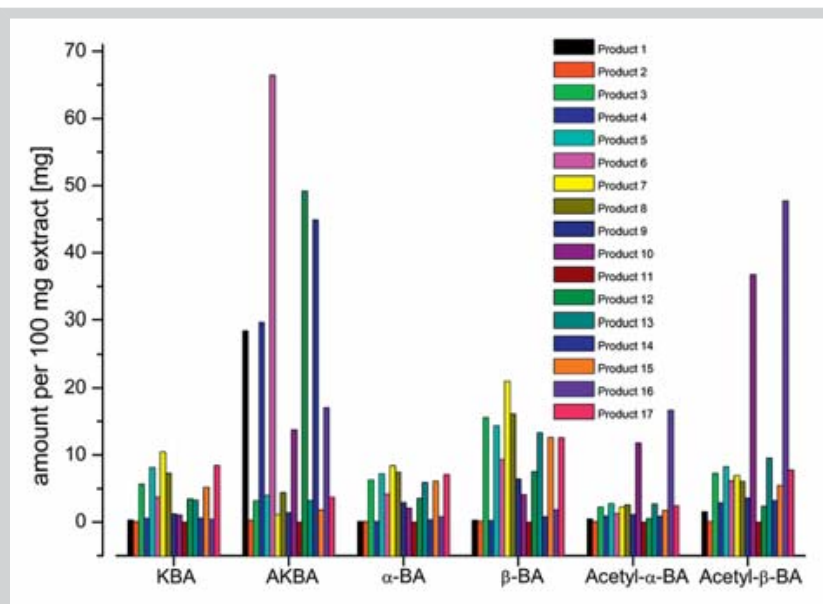

Fig. 2 Overview on the BA composition profile determined in the different botanical dietary supplements.

containing only traces suggests, in contradiction to what was declared on the label, the absence of $B$. serrata or the use of another Boswellia species such as $B$. frereana. Another product (10) displaying all basic label information revealed a ratio of non-acetylated to acetylated $B A s<1$, indicating the use of $B$. carterii or $B$. sacra [16]. In addition, based on the applied LC/MS analysis, two products $(16,17)$ revealed different BA contents from those declared on the label. Thus, only $7.7 \% \mathrm{~A} \beta \mathrm{BA}$ was determined in one product (17), corresponding to half of the amount mentioned on the label. The other product (16) claimed to contain $10 \mathrm{mg}$ AKBA, whereas an almost twofold higher amount of $17.1 \mathrm{mg}$ AKBA could be determined. Furthermore, two products $(6,12)$ did not declare the use of manipulated Boswellia gum resin extract being enriched in AKBA content reaching up to $66 \%$.

However, it should be noted in this context that the observed deviations from the declaration on the label may not always be attributed to deliberate adulteration, but in many cases results from the confusing characterization of Boswellia gum resin extracts and/or insufficient quality control measures applied by manufacturers. Thus, some Boswellia gum resin extracts are characterized by the organic acid content, others by the total acid, and again others by the BA content. As the BAs represent only a minor portion of the total acid content, a product claiming to contain $65 \%$ total acids or organic acids is not equivalent to a product claiming 60\% BAs. Moreover, different analytical methods may result in different boswellic BA content as demonstrated in the product information for AKBAmax ${ }^{\mathrm{TM}}$ [17], a commercially available Boswellia extract enriched in AKBA. Hence, the BA content was determined to be $70 \%$ when quantified with a titration method, but did not exceed 35-45\% when quantified with HPLC. In the first place, this may be attributed to the insufficient specificity of titration methods compared to chromatographic methods. Moreover, the varying spectrum of analytes covered by different analytical methods represents another reason for varying BA contents. This is also the reason why the total BA content determined in the present study turned out to be generally lower than the BA content labeled on the different products. It may be generally assumed that the declaration on the label is based on HPLC analysis, including more BAs than the six major BAs determined by the LC/MS method in this survey, leading, in consequence, to higher BA contents. Because of this diversity in charac- terizing Boswellia extracts and the varying analytical spectrum of the applied methods for quantification, it is very important for the manufacturer to get detailed information on the analytical methods and to ensure that a valid method is used to characterize the Boswellia extract in order to be able to properly evaluate its quality.

In the frame of misleading composition declarations, consumers find it increasingly difficult to actually estimate the quality and efficacy of dietary Boswellia products. Hence, they may correlate better efficacy with an increased acid content, although the declared acid content should not necessarily reflect the pharmacologically active BAs. They may be also misled by outdated literature or references to in vitro studies performed at dosages that can never be achieved in humans following oral administration. This was particularly evident for some studies cited $[11,18]$ in the case of product 16 using an AKBA-enriched extract. In fact, it was recently shown that AKBA is extensively bound to albumin in plasma, never approaching the concentrations needed to modulate the various targets of BAs even when large dosages of extracts were administered [9]. Furthermore, AKBA failed to inhibit 5-LO product formation in human whole blood, showing activity only in enzyme assays [19]. In addition, recent research revealed little relevance for 5-LO in the inflammatory response associated with osteoarthritis, the major clinical indication of Boswellia extracts $[20,21]$.

All products included in this survey are sold as botanical dietary supplements and are not intended to diagnose, treat, cure, or prevent any disease. Moreover, all US products clearly indicate that the statements made have not been evaluated by the Food and Drug Administration. Nevertheless, consumers should have access to reliable and accurately labeled botanical dietary supplements that do not claim effects that are hardly achieved. Surely many high-quality botanical dietary supplements are produced by reputable companies, but this cannot be always guaranteed, as demonstrated in the present survey. Thus, quality may still represent a paramount and complex issue when dealing with botanicals, as shown by the great differences in the chemical composition of BAs. Although all products but one declared the use of $B$. serrata extract, seven products out of seventeen have been identified where the BA content did not comply with the label claim, or other undeclared Boswellia extracts have been used instead of $B$. serrata or the Boswellia extract was even totally absent. Thus, in spite of increased regulations on botanical dietary supplements, the problem of mislabeling still exists and needs to be addressed by the manufacturers, so that consumers get greater confidence in the botanical dietary supplements they use.

\section{Materials and Methods \\ $\nabla$}

\section{Botanical dietary supplements}

The six US top-selling Boswellia dietary products were selected on the basis of the data from the market research company SPINS. One product was purchased from a food, drug, and mass merchandiser store, four from Natural Health Food Stores, and two from the Internet at amazon.com. The 11 European top-selling products were selected based on the data of the market research company IMS OTC and were purchased in local pharmacies. All tested products were assigned voucher numbers and representative voucher specimens have been deposited in the Central Laboratory of German Pharmacists, Eschborn, Germany. 


\section{Chemicals and reagents}

BAs ( $\alpha$-BA, $\beta$-BA, A $\alpha$ BA, A $\beta$ BA, AKBA, KBA) (purity > 99\%) were purchased from Phytoplan. Methanol of LC/MS quality was purchased from Carl Roth GmbH, ammonium formiate from Alfa Aesar $\mathrm{GmbH}$, and water Emsure ${ }^{\circledR}$ p. a. from Merck KGaA.

\section{Standard preparation}

Stock standard solutions of each BA were prepared by weighing into a 20 -mL volumetric flask $20 \mathrm{mg}$ of each BA standard and diluting it with $20 \mathrm{~mL}$ methanol to yield a concentration of $1 \mathrm{mg} /$ $\mathrm{mL}$ of each BA, respectively. Mixed spike solutions were prepared by mixing the appropriate amount of each boswellic stock stan-

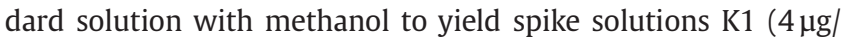
$\mathrm{mL})$, K2 $(12 \mu \mathrm{g} / \mathrm{mL})$, and $\mathrm{K} 3(24 \mu \mathrm{g} / \mathrm{mL})$.

\section{Sample preparation}

The contents of 10 tablets/capsules/sachets were pulverized and mixed well. An equivalent of $100 \mathrm{mg}$ Boswellia extract was weighed in a 50-mL centrifuge tube (Eco, PP, Roth, Art. AN78.1) and shaken with $20 \mathrm{~mL}$ of methanol for $60 \mathrm{~min}$ at $200 \mathrm{rpm}$ on a vertical shaker, followed by treatment in an ultrasonic bath for $30 \mathrm{~min}$ and centrifugation for $10 \mathrm{~min}$ at $2000 \mathrm{rpm}$. Four aliquots of $100 \mu \mathrm{L}$ of the clear supernatant were then transferred into four $10 \mathrm{~mL}$ volumetric flaks, respectively. In order to overcome any possible matrix interferences, the standard addition method was applied for the quantification of the BAs. For that purpose, the three spike solutions, $\mathrm{K} 1, \mathrm{~K} 2$, and $\mathrm{K} 3$, were added to the three aliquots of the clear supernatant, respectively, to yield three samples spiked with $4 \mu \mathrm{g} / \mathrm{mL}, 12 \mu \mathrm{g} / \mathrm{mL}$, and $24 \mu \mathrm{g} / \mathrm{mL}$, respectively. To one aliquot, no spike solution was added. Finally, $20 \mu \mathrm{L}$ of each sample solution were injected into the chromatographic system.

\section{Liquid chromatography-mass spectrometry analysis}

Apart from several analytical methods described in the literature for the quantification of BAs in Boswellia extracts and plasma, one HPTLC and one HPLC method have been reported for the analysis of KBA and AKBA in market formulations [22,23]. Moreover, only one HPLC analysis was devoted to the determination of the non-ketylated $\mathrm{BAs}, \beta$-BA, $\alpha-\mathrm{BA}, \mathrm{A} \beta \mathrm{BA}$, and $\mathrm{A} \alpha \mathrm{BA}$, besides KBA and AKBA in market formulations before [24]. As, however, the non-ketylated BAs do not possess a chromophore, the HPLC analysis of the complex extracts had to be conducted at a rather unselective wavelength of $210 \mathrm{~nm}$. In this regard, the application of LC/MS is advantageous because all BAs, even those without a chromophore, may be clearly identified via their typical $\mathrm{m} / \mathrm{z}$ values. Based on that background, the chromatographic and mass spectrometric parameters applied in a previously developed LC-MS method for the simultaneous determination of the six BAs in plasma have been applied for the analysis of BAs in the present study after its suitability had been assessed [25]. In brief, liquid chromatography was performed on an Agilent 1200 series equipped with a gradient pump with a vacuum degasser, an autosampler, and a column oven. A Hypersil ${ }^{\mathrm{TM}}$ BDS RP C18 column $(100 \times 4 \mathrm{~mm} ; 3 \mu \mathrm{m}$; Thermo scientific) and an upstream Gemini SecurityGuard ${ }^{\mathrm{TM}}$ cartridge (Phenomenex; $4 \times 3 \mathrm{~mm}$ ) were used for chromatography. Separation was achieved using a gradient program starting with $90 \%$ mobile phase A (methanol: water $90: 10,400 \mathrm{mg} / \mathrm{L}$ ammonium formate) and $10 \%$ mobile phase B (methanol: water $80: 20,400 \mathrm{mg} / \mathrm{L}$ ammonium formate), changing to $100 \%$ mobile phase A within 20 min. This was kept constant for 14 min before returning to the initial conditions within $1 \mathrm{~min}$. The total run time was $35 \mathrm{~min}$ at a flow rate of $0.4 \mathrm{~mL} / \mathrm{min}$.

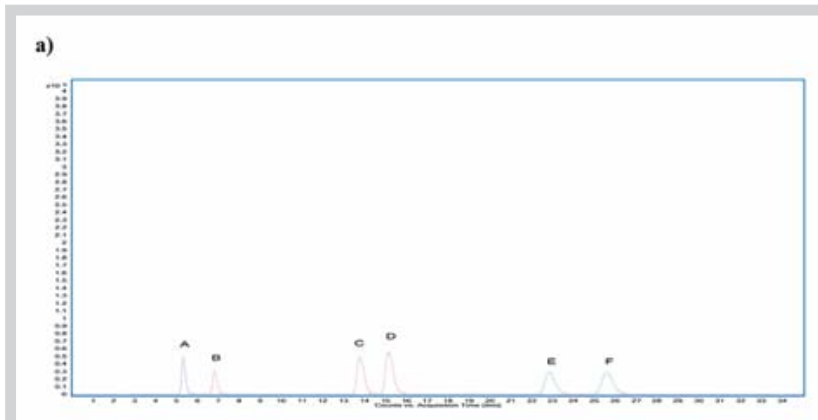

b)

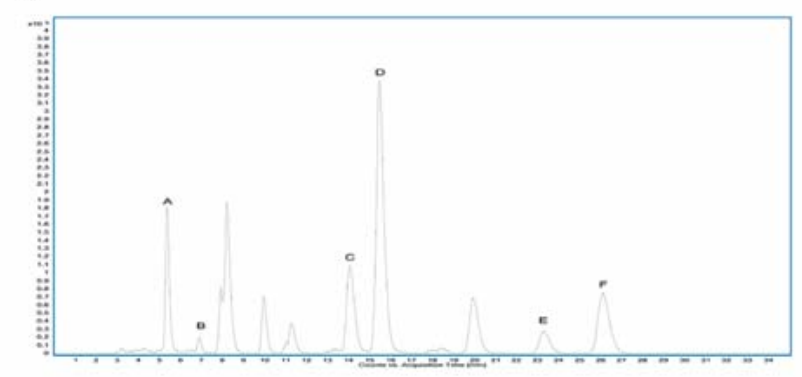

c)

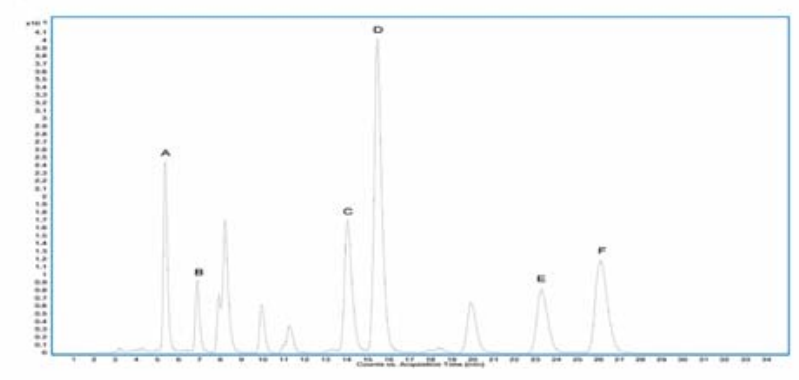

Fig. 3 Representative chromatograms of mixed standard solution containing KBA, AKBA, $\alpha-B A, \beta-B A, A \alpha B A, A \beta B A$ in methanol at a concentration of $1 \mathrm{\mu g} / \mathrm{mL}$ (a), product 7 prior to standard addition (b), and product 7 following standard addition at $2.4 \mu \mathrm{g} / \mathrm{mL}$ (c). $\mathrm{A}=\mathrm{KBA}, \mathrm{B}=\mathrm{AKBA}, \mathrm{C}=\alpha-\mathrm{BA}, \mathrm{D}=$ $\beta$-BA, $E=A \alpha B A, F=A \beta B A$. (Color figure available online only.)

The column oven was set to $40^{\circ} \mathrm{C}$ and the autosampler was kept at room temperature. MS analysis was performed in the negative SIM on an Agilent Triple Quadrupole LC/MS 6410 series (Agilent Technologies) equipped with an ESI source. The monitoring mass was set at $m / z 469.3$ for KBA, 511.5 for AKBA, 455.5 for $\beta$-BA and $\alpha-\mathrm{BA}$, and 497.4 for $\mathrm{Ac} \beta \mathrm{B} A$ and Ac $\alpha \mathrm{BA}$. The dwell time was chosen to be 200 ms. MassHunter ${ }^{\circledR}$ software was used for data acquisition and processing.

The fitness of the applied LC/MS method was assessed by judging the linearity, accuracy, and precision. The identity of the BAs was confirmed by their retention times and the standard addition approach. As can be seen exemplary in $\boldsymbol{O}$ Fig. $\mathbf{3}$, no interfering peaks are found in the chromatogram of the tested products, indicating that the formulation excipients do not interfere in the estimation of BAs. The accuracy of the method was evaluated by determining the recovery of each added BA standard at each concentration level in every product tested in addition to the mean recovery of each BA extending over all test products. The precision was assessed through the repetitive use of the same analytical procedure over the different matrices of all products $(n=17)$ on two consecutive days. Taking into consideration that no placebo matrix was available, the LOD for each BA was calculated as three 
Table 2 Summary of the validation results $(n=17)$.

\begin{tabular}{|c|c|c|c|c|c|c|c|c|c|c|}
\hline & & $\begin{array}{l}\text { Mean } \\
\text { content } \\
{[\mu \mathrm{g} / \mathrm{mL}]}\end{array}$ & $\begin{array}{l}\text { Mean } \\
\text { recovery } \\
{[\%]}\end{array}$ & $\begin{array}{l}\text { Min. } \\
\text { recovery } \\
{[\%]}\end{array}$ & $\begin{array}{l}\text { Max. } \\
\text { recovery } \\
{[\%]}\end{array}$ & $\begin{array}{l}\text { Mean } \\
\text { SD } \\
{[\mu \mathrm{g} / \mathrm{mL}]}\end{array}$ & $\begin{array}{l}\text { Mean } \\
\text { CV [\%] }\end{array}$ & Mean $\mathbf{R}^{2}$ & $\begin{array}{l}\text { LOQ } \\
{[\mu \mathrm{g} / \mathrm{mL}]}\end{array}$ & $\begin{array}{l}\text { LOD } \\
{[\mu \mathrm{g} / \mathrm{mL}]}\end{array}$ \\
\hline \multirow[t]{3}{*}{$\mathrm{KBA}[\mu \mathrm{g} / \mathrm{mL}]$} & 0.4 & 0.3987 & 99.69 & 95.40 & 102.10 & 0.00967 & 2.43 & \multirow[t]{3}{*}{0.9998} & \multirow[t]{3}{*}{0.060} & \multirow[t]{3}{*}{0.020} \\
\hline & 1.2 & 1.2021 & 100.17 & 98.83 & 102.56 & 0.01611 & 1.34 & & & \\
\hline & 2.4 & 2.3992 & 99.97 & 99.49 & 100.23 & 0.00644 & 0.27 & & & \\
\hline \multirow[t]{3}{*}{ AKBA $[\mu \mathrm{g} / \mathrm{mL}]$} & 0.4 & 0.4007 & 100.17 & 95.20 & 105.50 & 0.00939 & 2.34 & \multirow[t]{3}{*}{0.9998} & \multirow[t]{3}{*}{0.007} & \multirow[t]{3}{*}{0.002} \\
\hline & 1.2 & 1.1989 & 99.90 & 96.94 & 102.68 & 0.01567 & 1.31 & & & \\
\hline & 2.4 & 2.4005 & 100.02 & 99.47 & 100.61 & 0.00627 & 0.26 & & & \\
\hline \multirow[t]{3}{*}{$\alpha-\mathrm{BA}[\mu \mathrm{g} / \mathrm{mL}]$} & 0.4 & 0.3900 & 97.34 & 84.25 & 103.03 & 0.02179 & 5.6 & \multirow[t]{3}{*}{0.9988} & \multirow[t]{3}{*}{0.259} & \multirow[t]{3}{*}{0.085} \\
\hline & 1.2 & 1.2177 & 101.48 & 98.32 & 108.75 & 0.03631 & 2.98 & & & \\
\hline & 2.4 & 2.3929 & 99.70 & 98.25 & 100.34 & 0.01454 & 0.61 & & & \\
\hline \multirow[t]{3}{*}{$\beta-B A[\mu \mathrm{g} / \mathrm{mL}]$} & 0.4 & 0.3940 & 98.50 & 87.63 & 107.58 & 0.0215 & 5.46 & \multirow[t]{3}{*}{0.9990} & \multirow[t]{3}{*}{0.156} & \multirow[t]{3}{*}{0.051} \\
\hline & 1.2 & 1.2100 & 100.83 & 95.79 & 106.88 & 0.03582 & 2.96 & & & \\
\hline & 2.4 & 2.3960 & 99.83 & 98.63 & 100.84 & 0.01433 & 0.60 & & & \\
\hline \multirow[t]{3}{*}{$\mathrm{A} \alpha \mathrm{BA}[\mu \mathrm{g} / \mathrm{mL}]$} & 0.4 & 0.3920 & 97.99 & 93.95 & 101.38 & 0.0089 & 2.29 & \multirow[t]{3}{*}{0.9996} & \multirow[t]{3}{*}{0.144} & \multirow[t]{3}{*}{0.047} \\
\hline & 1.2 & 1.2134 & 101.12 & 99.23 & 103.36 & 0.01497 & 1.23 & & & \\
\hline & 2.4 & 2.3946 & 99.78 & 99.33 & 100.15 & 0.00599 & 0.25 & & & \\
\hline \multirow[t]{3}{*}{$\mathrm{A} \beta \mathrm{BA}[\mu \mathrm{g} / \mathrm{mL}]$} & 0.4 & 0.3993 & 99.82 & 95.83 & 105.25 & 0.01080 & 2.69 & \multirow[t]{3}{*}{0.9998} & \multirow[t]{3}{*}{0.247} & \multirow[t]{3}{*}{0.081} \\
\hline & 1.2 & 1.2012 & 100.10 & 97.08 & 102.32 & 0.01792 & 1.49 & & & \\
\hline & 2.4 & 2.3995 & 99.98 & 99.54 & 100.59 & 0.00717 & 0.30 & & & \\
\hline
\end{tabular}

times the corresponding standard deviation of the mean intercept divided by the slope of the mean standard addition calibration curve. The LOQ for each BA was calculated as 10 times the corresponding standard deviation of the mean intercept divided by the slope of the mean standard addition calibration curve. The results are summarized in 0 Table 2 . Both the high accuracy reflected in the high recovery rates as well as the good precision at each concentration level for each BA in different matrices verify the ruggedness of the applied method and its independence from minor deviations in the experimental conditions, especially in the matrix composition of the different products tested.

\section{Conflict of Interest}

$\nabla$

P.M. and A.R. are employed by Indena, the producer of Casperome $^{\circledR}$. C.A. was employed by Indena at the time of the study. The other authors have no conflict of interest.

\section{References}

1 Peregoy JA, Clarke TC, Jones LI, Stussman BJ, Nahin RL. Regional variation in use of complementary health approaches by U.S. adults. NCHS Data Brief 2014; 146: 1-8

2 World Health Organization. Traditional medicine. Fact Sheet $\mathrm{N}^{\circ} 134$. Available at http://www.who.int/mediacentre/factsheets/2003/fs134/ en/. Accessed August 17, 2015

3 World Health Organization. National policy on traditional medicine and regulation on herbal medicine. Report of a WHO global survey. Geneva: World Health Organization; 2005

4 Global Industry Analyst, Inc. Herbal supplements and remedies - global strategic business report. Available at http://www.prweb.com/releases/herbal_supplements/herbal_remedies/pr.web9260421.htm. Accessed March 14, 2016

5 Moraes CDF, Still DW, Lum MR, Hirsch AM. DNA-based authentication of botanicals and plant-derived dietary supplements: where have we been and where are we going? Planta Med 2015; 81: 687-695

6 FitzloffJ, Yat P, Lu Z, Awang DVC, Arnason JT, van Breemen RB, Hall T, Blumenthal $M$, Fong HHS. Perspectives on the quality assurance of ginseng products in North America. In: Huh H, Choi KJ, Kim YC, editors. Advances in Ginseng Research - Proceedings of the 7th International Symposium on Ginseng. Seoul, Korea: The Korean Society of Ginseng; 1998: 138-145
7 Monmaney T. Remedy's U.S. sales zoom, but quality control lags. The Los Angeles Times 1998; August 31: A1-A10

8 Schulz V, Hubner WD, Ploch M. Clinical trials with phyto-psychopharmacological agents. Phytomedicine 1997; 4: 379-387

9 Abdel-Tawab M, Werz O, Schubert-Zsilavecz M. Boswellia serrata: an overall assessment of in vitro, preclinical, pharmacokinetic and clinical data. Clin Pharmacokinet 2011; 50: 349-369

10 Nieman DC, Shanely RA, Luo B, Dew D, Meaney MB, Sha W. A commercialized dietary supplement alleviates joint pain in community adults: a double-blind, placebo-controlled community trial. Nutr J 2013; 12: 154

11 Safayhi H, Mack T, Sabieraj J, Anazodo MI, Subramanian LR, Ammon HP. Boswellic acids: novel, specific, non-redox inhibitors of 5-lipoxygenase. J Pharmacol Exp Ther 1992; 261: 1143-1146

12 Siemoneit U, Pergola C, Jazzar B, Northoff H, Skarke C, Jauch J, Werz O. On the interference of boswellic acids with 5-lipoxygenase: mechanistic studies in vitro and pharmacological relevance. Eur J Pharmacol 2009; 606: $246-254$

13 Tausch L, Henkel A, Siemoneit U, Poeckel D, Kather N, Franke L, Hofmann B, Schneider G, Angioni C, Geisslinger G, Skarke C, Holtmeier W, Beckhaus $T$, Karas M, Jauch J, Werz O. Identification of human cathepsin G as a functional target of boswellic acids from the anti-inflammatory remedy frankincense. I Immunol 2009; 183: 3433-3442

14 Siemoneit U, Koeberle A, Rossi A, Dehm F, Verhoff M, Reckel S, Maier TJ, Jauch J, Northoff H, Bernhard F, Doetsch V, Sautebin L, Werz O. Inhibition of microsomal prostaglandin E2 synthase-1 as a molecular basis for the anti-inflammatory actions of boswellic acids from frankincense. $\mathrm{Br}$ J Pharmacol 2011; 162: 147-162

15 Bannoa N, Akihisa T, Yasukawa K, Tokuda H, Tabata K, Nakamura Y Nishimura R, Kimura Y, Suzuki T. Anti-inflammatory activities of the triterpene acids from the resin of Boswellia carteri. J Ethnopharmacol 2006; 107: 249-253

16 Frank A, Unger $M$. Analysis of frankincense from various Boswellia species with inhibitory activity on human drug metabolising cytochrome P450 enzymes using liquid chromatography mass spectrometry after automated on-line extraction. J Chromatogr A 2006; 1112: 255-262

17 Frutarom Select Line: AKBAmax. Available at http://www.selectline. com/akbamax-p2950-en.html. Accessed August 26, 2015

18 Ammon HP, Safayhi H, Mack T, Sabieraj J. Mechanism of antiinflammatory actions of curcumine and boswellic acids. J Ethnopharmacol 1993; 38: $113-119$

19 Poeckel D, Werz O. Boswellic acids: biological actions and molecular targets. Curr Med Chem 2006; 13: 3359-3369

20 Siemoneit U, Pergola C, Jazzar B, Northoff H, Skarke C, Jauch J, Werz O. On the interference of boswellic acids with 5-lipoxygenase: mechanistic 
studies in vitro and pharmacological relevance. Eur J Pharmacol 2009; 606: 246-254

21 Du Z, Liu Z, Ning Z, Liu Y, Song Z, Wang C, Lu A. Prospects of boswellic acids as potential pharmaceutics. Planta Med 2015; 81: 259-271

22 Shah SA, Rathod IS, Suhagia BN, Patel DA, Parmar VK, Shah BK, Vaishnavi $V M$. Estimation of boswellic acids from market formulations of Boswellia serrata extract and 11 -keto- $\beta$-boswellic acid in human plasma by high-performance thin-layer chromatography. J Chromatogr B Analyt Technol Biomed Life Sci 2007; 848: 232-238

23 Shah SA, Rathod IS, Suhagia BN, Pandya SS, Parmar VK. A simple highperformance liquid chromatographic method for the estimation of boswellic acids from the market formulations containing Boswellia serrata extract. J Chromatogr Sci 2008; 46: 735-738

24 Ganzera M, Khan IA. A reversed phase high performance liquid chromatography method for the analysis of boswellic acids in Boswellia serrata. Planta Med 2001; 67: 778-780

25 Gerbeth K, Meins J, Kirste S, Momm F, Schubert-Zsilavecz M, Abdel-Tawab $M$. Determination of major boswellic acids in plasma by high-pressure liquid chromatography/mass spectrometry. J Pharm Biomed Anal 2011; 56: 998-1005 